\title{
A design integrated parametric tool for real-time Life Cycle Assessment - Bombyx project
}

\section{Conference Paper}

Author(s):

Basic, Saso; Hollberg, Alexander (D); Galimshina, Alina; Habert, Guillaume

Publication date:

2019

Permanent link:

https://doi.org/10.3929/ethz-b-000370474

Rights / license:

Creative Commons Attribution 3.0 Unported

Originally published in:

IOP Conference Series: Earth and Environmental Science 323(1), https://doi.org/10.1088/1755-1315/323/1/012112 
PAPER • OPEN ACCESS

\section{A design integrated parametric tool for real-time Life Cycle Assessment - Bombyx project}

To cite this article: S Basic et al 2019 IOP Conf. Ser.: Earth Environ. Sci. 323012112

View the article online for updates and enhancements. 


\title{
A design integrated parametric tool for real-time Life Cycle Assessment - Bombyx project
}

\author{
Basic $S^{1}$, Hollberg $A^{1}$, Galimshina $A^{1}$, Habert $G^{1}$ \\ ${ }^{1}$ Institute of Construction and Infrastructure Management, Chair of Sustainable \\ Construction, Swiss Federal Institute of Technology (ETH Zurich), Stefano Franscini \\ Platz 5, 8093 Zurich, Switzerland \\ basic@ibi.baug.ethz.ch
}

\begin{abstract}
Life Cycle Assessment (LCA) has become a widely accepted method for environmental assessment of buildings, but is still not commonly applied in design practice. The biggest potential for optimization and reduction of GHG emissions lies in the early stages of the design process. Therefore, a design-integrated approach for LCA is needed. The goal of this paper is to describe the development of a parametric LCA tool for application in early design stages in the Swiss context. The envisioned users of the tool are primarily architecture and engineering students, but also practitioners. The integration of LCA throughout the design process is solved through a modular strategy. In the early stage, pre-defined components are selected to model a complete LCA. In the following design steps when more information is available, individual materials can be input with higher level of detail. The Bombyx tool is developed as a plugin for Grasshopper based on Rhinoceros3D and includes an SQL material and component database. Users are able to choose different materials and building systems and quickly modify the building's geometry while continuously receiving the calculated environmental impact in real-time. Visualization of the results, e.g. colour code indicate how the design performs in relation to a benchmark or optimization potential. The project is developed in open source to broaden the user and developer community and foster new ideas, designs and implementations in Bombyx.
\end{abstract}

\section{Introduction}

The built environment is responsible for more than one third of global greenhouse gas (GHG) emissions and has the largest potential for delivering long-term, significant and cost-effective GHG emission reductions [1]. Until now, the efforts to reduce GHG emissions mainly focused on the use phase of buildings. These measures have successfully reduced the operational energy demand for new and existing buildings and the limits for energy optimization in the use phase have mostly been achieved [2]. For new residential buildings, the so-called embodied GHG emissions related to material production, construction, maintenance and end of life of buildings account for half of the total emissions within an assumed life cycle of 50 years [3]. Therefore, the whole life cycle of buildings has to be evaluated. Life Cycle Assessment (LCA) has become a widely accepted method for environmental assessment of buildings in a scientific context, but is still not commonly applied in design practice. In 
the rare case that it is applied, LCA is used as post-design evaluation as a mandatory part of sustainability certification schemes. However, post-design evaluation through LCA is not sufficient on its own, as it does not improve the environmental performance of the design [4].

In general, decisions made in the early stages of the design process, have the greatest influence, as they set general conditions for the subsequent design process [5] (see Figure 1). As such, the early design phase has the highest influence on costs [5], operational energy demand [6] and the environmental impacts [7]. Therefore, the biggest potential for optimization and reduction of GHG emissions lies in the early stages of the design process. LCA needs to be applied in early design stages to allow for holistic environmental optimization of the building.

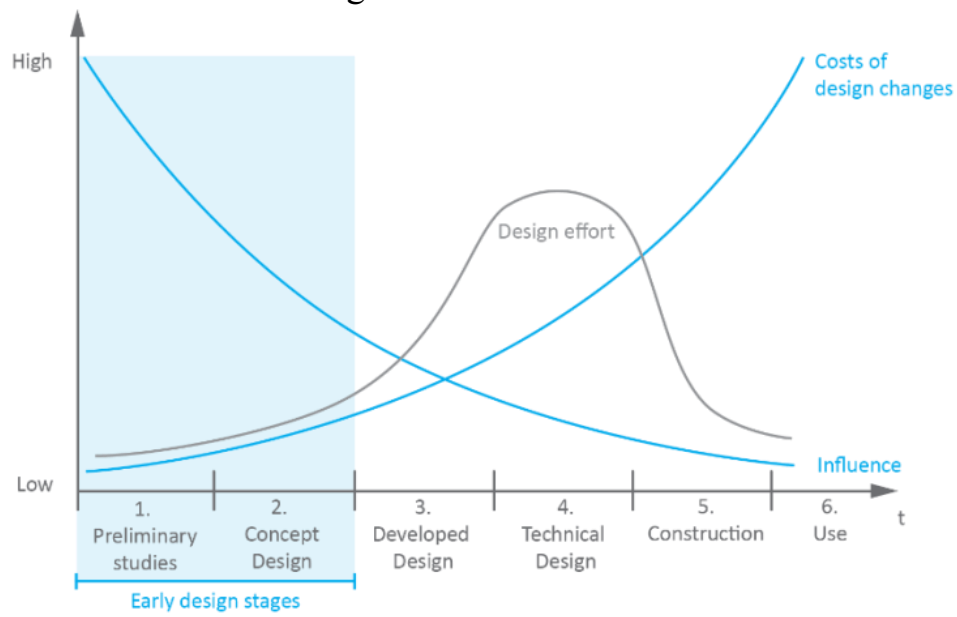

Figure 1. Influence of the early design stages (based on [5]).

Parametric design has been known for a long time [8], but gained popularity in architecture and design in the last ten to fifteen years. The main advantage of the parametric approach is the possibility to easily generate numerous different design variants. Lawson observed that many designers express a need to generate and assess alternative design ideas [9]. With the help of a parametric model, architects can fulfil this need. Once a parametric model has been developed, the generation of further design alternatives is nearly effortless. As such, the parametric approach is ideal for optimization, because design optimization is an iterative process of generating, evaluating, and comparing design variants. Parametric design allows for very quick generation of design solutions, but for time-efficient optimization, methods and tools for quick analysis are needed as well.

There is a wide range of parametric tools for building performance assessment, including energy performance, daylight availability or computational fluid dynamics. While a number of LCA tools have been developed in the last years [10], [11], only a few follow a parametric approach, e.g. Tortuga [12] or CAALA [13]. Regarding the Swiss contexts, there is a lack of adequate tools for design optimization in early design stages. Current tools are either over-simplified or too complex. Simplified tools aim to quickly estimate the embodied impact in early design stages (for example SIA 2040 Excel tool [14]), but they cannot be used to improve the building design, because of limited material options. Expert software (for example SimaPro) allow modelling the building and all materials in high detail, but inputting all necessary information is very time-consuming. Software primarily developed for engineers (for example Lesosai) is well suited for certification, but the effort to compare various design options including different geometries is high. The aim of applying LCA in early design stages should be to improve the building's environmental performance. This is not possible with the current set of tools using Swiss LCA data.

The goal of this paper is to describe the development of a parametric LCA tool for application in early design stages in the Swiss context. The envisioned users of the tool are primarily architecture and 
engineering students, but also practitioners. Furthermore, the tool is developed as an open source project to allow adaption to other national contexts and attract further developers in the future.

The paper first explains the method behind the tool and the implementation in form of a plug-in for Grasshopper 3D, a parametric design software based on Rhinoceros 3D. Then the intended application in a teaching project is explained and an example of using the tool in the design process is provided.

\section{Concept of parametric LCA}

The basic concept of the parametric LCA (PLCA) approach is combining the principles of parametric design with a simplified LCA method [15]. Here, the concept is used as described by Hollberg [16] and adapted to the Swiss context. In the following, the workflow of using the approach in the design process and the calculation procedures are described separately.

\subsection{Workflow in the design process}

Designer can typically influence the environmental performance of a building by three categories of parameters: 1) geometry, 2) materials, and 3) heating, ventilation, air conditioning (HVAC) systems. Each category consists of a number of parameters, such as orientation, dimensions, window area, etc. for the geometry. All parameters are input in a parametric LCA model.

The geometry is defined using a 3D model of surfaces, similar to a thermal model. The model includes, ceilings, balconies, etc. that might not be needed for calculating the energy demand but are necessary for calculating the embodied impact. The building is structured into eleven building elements (see Table 1). Each element consists of a number of components according to the Swiss structure for cost estimation e-BKP-H SN 506 511. The components are also the basis for defining the reference service life (RSL) according to SIA 2032.

The building materials are input by defining the materials for each element. This can be done in two level of details. 1) Selecting from typical pre-defined components, e.g. a timber-frame structure with mineral wool insulation (see Figure 2), or 2) by defining layers and selecting each material separately (see Figure 3). The second approach provides more flexibility and allows for a detailed assessment while the first approach reduces the effort to input the materials significantly and is therefore ideal for early design stages.

The technical equipment is always input on component level and based on the energy reference area (ERA) of the building, which equals the heated gross floor area. 
Table 1. Structure of building elements and components

\begin{tabular}{ll}
\hline Building element & BKP-H Component \\
\hline 1. Base slab & $\begin{array}{l}\text { C1 Base slab, foundation } \\
\text { G2 Floor covering }\end{array}$ \\
\hline 2. Exterior wall under ground & $\begin{array}{l}\text { C2.1 A Exterior wall under ground } \\
\text { E1 Exterior wall finishing under ground }\end{array}$ \\
\hline 3. Exterior wall above ground & C2.1B Exterior wall above ground \\
& E2 Exterior wall finishing above ground \\
& G3 Interior wall finishing \\
\hline 4. Window & E3 Window \\
\hline 5. Interior wall & C2.2 Interior wall \\
& G3 Interior wall finishing \\
\hline 6. Partition wall & G1 Partition wall \\
& G3 Interior wall finishing \\
\hline 7. Column & C3 Column \\
\hline 8. Ceiling & C4.1 Ceiling \\
& G2 Floor covering \\
\hline 9. Balcony & G4 Interior ceiling/roof finishing \\
\hline 10. Roof & C4.3 Balcony \\
& C4.4 Roof \\
\hline 11. Technical equipment & F1 Roof covering \\
& G4 Interior ceiling/roof finishing \\
\hline & D1 Electric equipment \\
D5.2 Heat generation \\
D5.3 / D5.4 Heat distribution and delivery \\
\hline
\end{tabular}

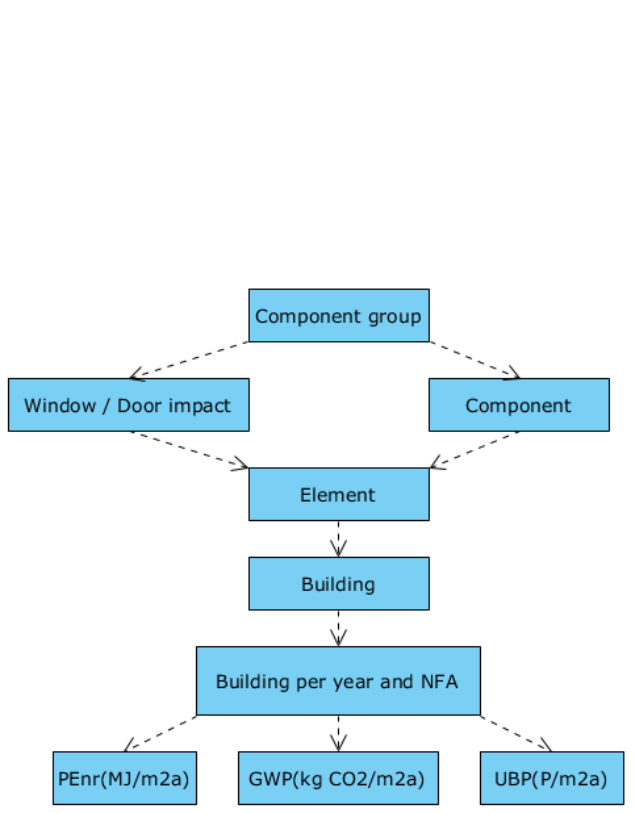

Figure 2. Component level

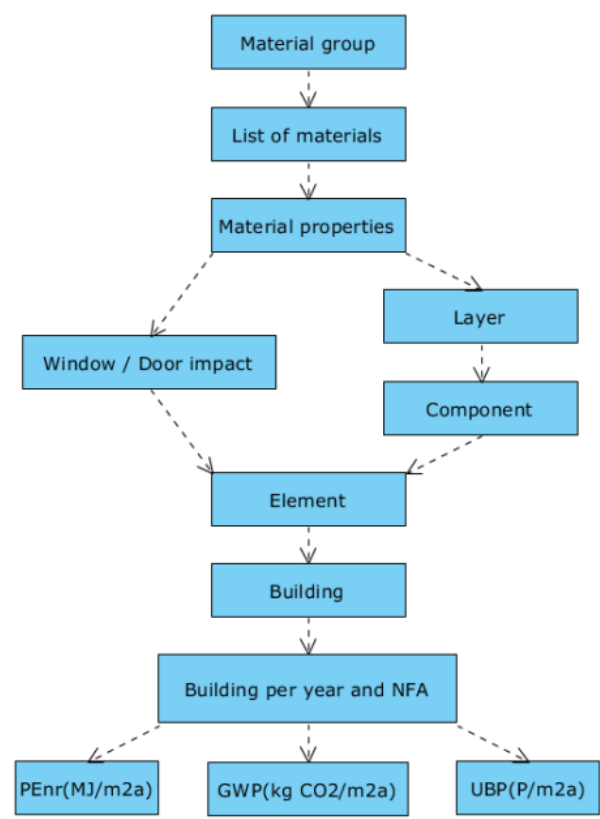

Figure 3. Material level 


\subsection{Calculation}

The approach presented here combines the primary energy demand and environmental impact of the building in the term impact. It distinguishes between the operational impact $\left(\mathrm{I}_{\mathrm{O}}\right)$ resulting from the operational energy use of the building (life cycle module B6 according to EN 15978 [17]) and the embodied impact $\left(\mathrm{I}_{\mathrm{E}}\right)$ resulting from production and the end of life of the building (modules A1-A3, C3, and $\mathrm{C} 4$ ). The replacement of building components (module $\mathrm{B} 4$ ) is also considered as $\mathrm{I}_{\mathrm{E}}$. The life cycle impact $\left(\mathrm{I}_{\mathrm{LC}}\right)$ is the sum of $\mathrm{I}_{\mathrm{E}}$ and $\mathrm{I}_{\mathrm{O}}$ (see Equation 1).

$$
I_{L C}=I_{O}+I_{E}
$$

\subsubsection{Embodied impact}

The embodied impact $\left(\mathrm{I}_{\mathrm{E}}\right)$ is calculated by multiplying the mass of each material $\left(\mathrm{M}_{\mathrm{j}}\right)$ by the specific embodied impact factor of the material $\left(\mathrm{IF}_{\mathrm{E}, \mathrm{j}}\right)$ (see Equation 2). To determine the mass, first of all, the areas of the different building element surfaces have to be calculated. The surface areas are then multiplied by the thickness and density of the specific material. The density is imported from the KBOB database Ökobilanzdaten im Baubereich [18] together with the specific $\mathrm{IF}_{\mathrm{E}}$. Furthermore, the number of replacements $\left(\mathrm{R}_{\mathrm{j}}\right)$ is considered. In this way, the $\mathrm{I}_{\mathrm{E}}$ of every component is calculated and summed up to obtain the $\mathrm{I}_{\mathrm{E}}$ of the entire building.

$$
I_{E}=\sum_{j}\left(M_{j} \times I F_{E, j} \times\left(1+R_{j}\right)\right)
$$

For some materials, such as windows, the KBOB database provides the IE per surface area of the element. In this case, the element area $A_{j}$ can directly be multiplied with the IE.

$$
I_{E}=\sum_{j}\left(A_{j} \times I F_{E, j} \times\left(1+R_{j}\right)\right)
$$

To calculate the number of replacements (Rj), the reference study period (RSP) is divided by the reference service life (RSL) of the building component. The RSP for residential buildings is 60 years in Switzerland. The RSL is defined in SIA 2032 [19]. $\mathrm{R}$ is calculated according to equation 4 . For example, if a painting possesses a RSL of 20 years, it has to be renewed twice within an RSP of 60 years, so R equals 2.

$$
R_{j}=\left\lceil R S P / R S L_{j}\right\rceil-1
$$

\subsubsection{Operational impact}

The operational impact $\mathrm{I}_{\mathrm{O}}$ consists of the sum of all different kinds of operational energy demand during the use phase $\left(\mathrm{ED}_{\mathrm{i}}\right)$ multiplied by the operational impact factor of the energy carrier $\left(\mathrm{IF}_{\mathrm{O}, \mathrm{i}}\right)$ (see Equation 5). ED refers to the final energy demand and is calculated with reference to one year of operation. Therefore, the sum is multiplied by the number of years of the reference study period (RSP). The operational impact factor $\left(\mathrm{IF}_{\mathrm{O}}\right)$ depends on the energy carrier employed and is taken from the KBOB database.

$$
I_{O}=\sum_{i}\left(E D_{i} \times I F_{O, i}\right) \times R S P
$$

The ED is calculated according to Swiss standards. The calculation approach is described in SIA 380/1 [20]. Various building categories (e.g. multi and single family houses, schools, office buildings etc.) can be calculated based on pre-defined parameters as the room temperature, floor area per person, occupancy schedule, etc. SIA provides data for 40 different climate stations in Switzerland including annual and monthly average temperatures, altitude above sea level and solar irradiation of South, East, West, North and Horizontal orientations. Here, we only include the calculation of residential buildings 
to simplify the process. The ED consists of space heating, hot water demand and electricity demand for appliances and lighting. The standard uses a quasi-steady state monthly energy balance to calculate the space heating demand. The monthly values are summed up to the annual value and added to the warm water demand to provide ED for heating. We use the simplified approach of SIA with fixed global values for the hot water and electricity demand.

The results of SIA 380/1 are the useful energy demand of a building. To account for different kinds of losses within a building and for the performance of the selected heating source (e.g. heat pump or gas-condensing boiler), the performance factor (PF) is used. The PF is introduced to describe different types of building services with one systematic approach. To calculate the final energy demand, the useful energy demand is divided by the PF.

The ED can also be calculated using other tools for building performance simulation, e.g. Honeybee/Energyplus or HIVE, and manually input in Bombyx. This allows for also evaluating more complex building with complex HVAC systems.

The impact factors (IFO,i, IFE,j) depend on the indicators chosen for the LCA. If more than one indicator is used, the impact factors are written as vectors of the indicators applied. In consequence, the resulting impact (IO, IE) is a vector as well. The advantage of using vectors for the impact factors is that the indicators chosen for evaluation can be easily modified depending on the available data. Equation 7 shows IFO, $i$ and IFE, $j$ for the indicators used by the Swiss KBOB database for building materials. UBP stand for Umweltbelastungspunkte or eco points, a single score indicator based on the Swiss Method of Ecological Scarcity [21]. Eco factors are used to relate between the actual emission situation in Switzerland and political targets [22]. The primary energy demand is provided as renewable part (Per) and non-renewable part (PEnr). Furthermore, Global Warming Potential 100 (GWP) expressed in CO2equivalent as indicator for climate change is used as defined by IPCC [23].

$$
I F_{O, i}=\left(\begin{array}{c}
U B P \\
P E n r \\
P E r \\
G W P
\end{array}\right), I F_{E, j}=\left(\begin{array}{c}
U B P \\
P E n r \\
P E r \\
G W P
\end{array}\right)
$$

\section{Software implementation}

Bombyx is designed and implemented as a plug-in for Grasshopper (GH), an add-on Rhinoceros 3D. The plug-in is free and available at Food4Rhino1. The core of the application is developed in C\#. Grasshopper is based on visual programming and allows users to create scripts and components in C\#, VB.NET and Python to further customise the functionality of Bombyx. The project is open source, so users can download the whole source code from GitHub2. They can also contribute with ideas and their own implementations.

The material and component data used in Bombyx is stored in a database. Further adjustments, as well as adding new materials and components can be done via specially prepared web page. Here, guest users can view all materials and components used by Bombyx and trusted users get the option to edit materials and components or add new ones. The SQL scripts to generate data tables are also provided on GitHub, but users need to setup and manage their own SQL server, where their database will reside. This could be useful to use Bombyx in other countries with other national databases in the future, for example.

\footnotetext{
${ }^{1}$ The latest version of Bombyx and example files can be downloaded from: https://www.food4rhino.com/app/bombyx

${ }^{2}$ GitHub source: https://github.com/Bombyx-ETH/Bombyx
} 
The geometry can be directly defined within GH or drawn in Rhinoceros and automatically loaded into GH. For the second approach, a pre-defined layer structure using the eleven elements shown in Table 1 is provided (see Figure 4).

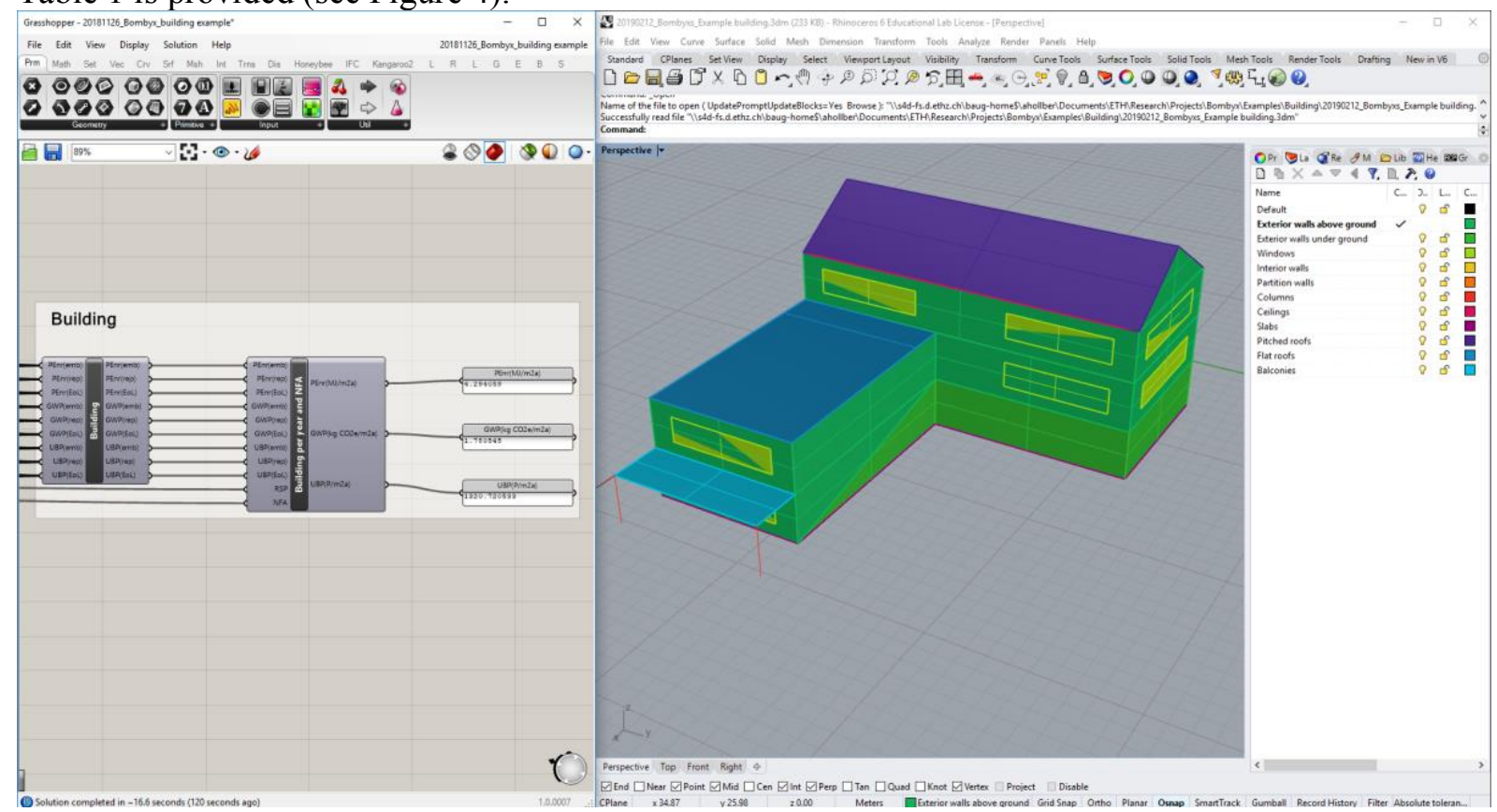

Figure 4. Bombyx plug-in in GH (left) and geometry with pre-defined layers (right).

Currently, Bombyx provides the LCA results as number in the GH viewport. They can be output on different levels of detail, for example the whole building per year, or individual components and materials separated into the life cycle stages production or end of life. A visual feedback is very import for designers [24] and will be implemented in the following versions of Bombyx (see section Future Developments).

\section{Application for teaching}

Bombyx will be used in the course Building Materials and Sustainability in the fall semester 2019 at ETH Zürich. It will be part of the Master course Integrated building systems and linked a design studio. A common question and concern of teachers of design studio when using performance assessment in the design process is whether this comes at the expense of the architectural design quality [25]. Clearly, the course aims at improving both environmental performance and architectural quality. We will therefore track both aspects using a graph to plot the architectural quality and the environmental quality (see Figure 5). Rating the architectural quality is not easy and can be partially subjective. Therefore, the final grades the students received in the design studio will be used as indicator for architectural quality. The environmental quality will be assessed with a simple Bombyx calculation. The comparison of students having followed the course with those who have not will be a direct evaluation of the quality of the course. If the environmental assessment has been effectively integrated during the design process, we expect that projects from our students will have a better environmental performance and a similar architecture quality, but this needs to be tested. 


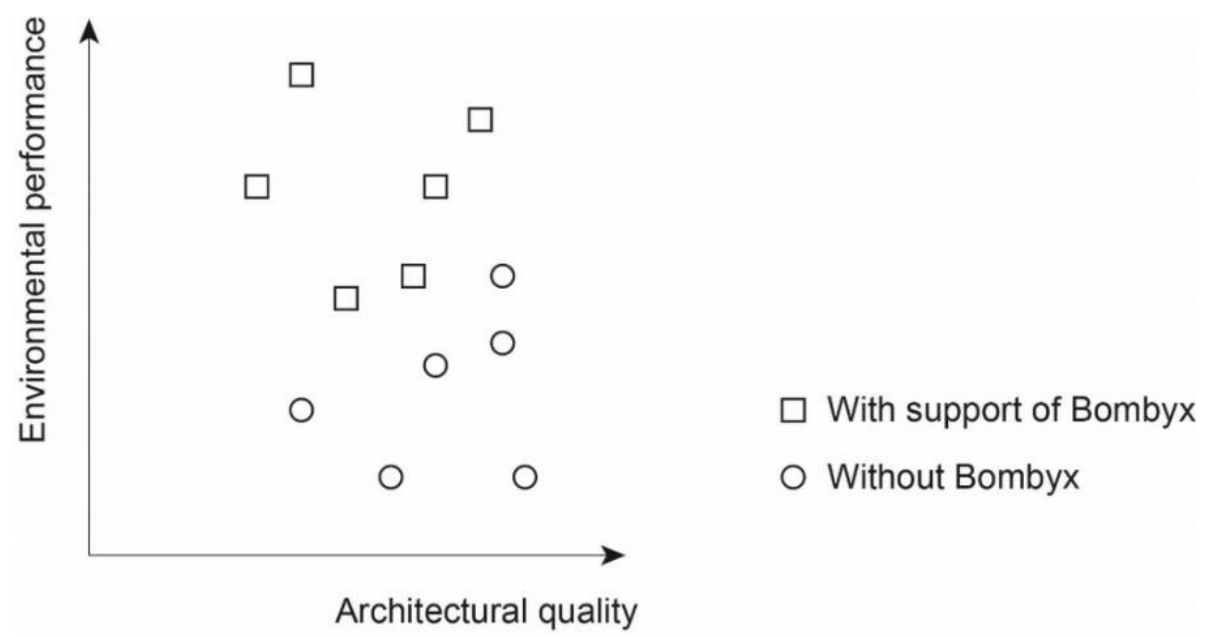

Figure 5. Expected result of the comparison between the final results of design studios of groups that used Bombyx with students that did not attend the course and apply the tool.

\section{Future developments}

The students' feedback will also be used to improve the Bombyx tool in the future. As mentioned above, a major task for the next version will be the integration of visualisations. We will follow two strategies. To provide insights into the relation between operational and embodied impact and the share of impact each components is responsible of, we will implement sunburst diagrams as shown by Kiss and Szalay [26] (see Figure 6). In addition, we will use the 3D model to map the results onto the model as previously shown by Röck et. al. [27] (see Figure 7). This approach allows for several types of result visualisations. The impact of each component can be directly shown on the specific component using a colour scale from green to red for example. Furthermore, to potential for improvement can be indicated by visualising the distance to a target or best-practice solution.

A future development could also integrate assumptions for buildings that have not yet been specified in early design stages. Benchmarks that can serve as reference values for Switzerland are provided by Hollberg, Lützkendorf, and Habert [28], for example. In addition, minimum and maximum values can be given out to provide a range of possible final results and show the uncertainty due to these assumptions. 


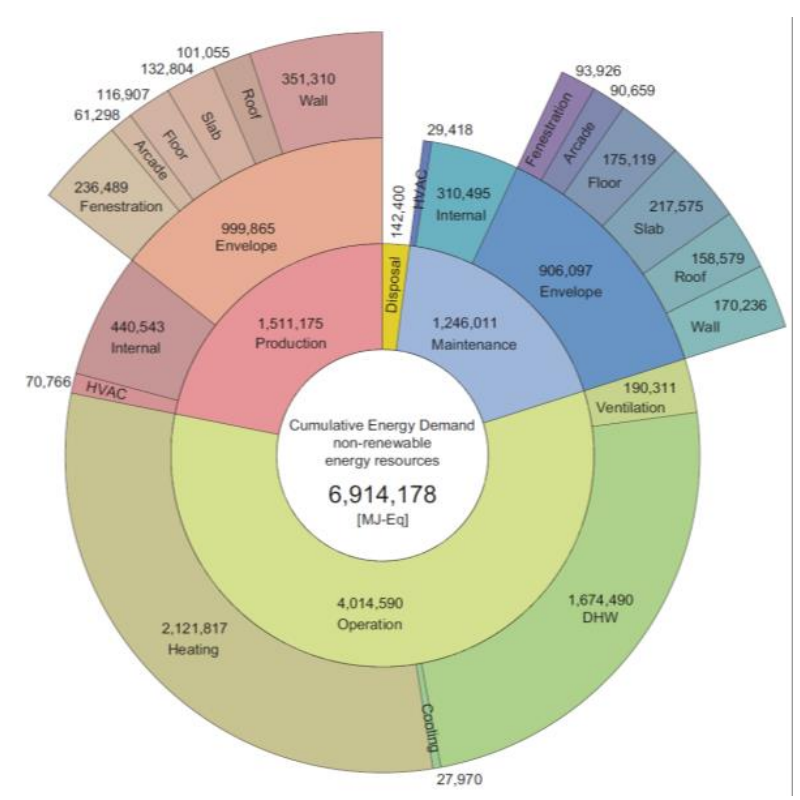

Figure 6. Sunburst diagram [26].

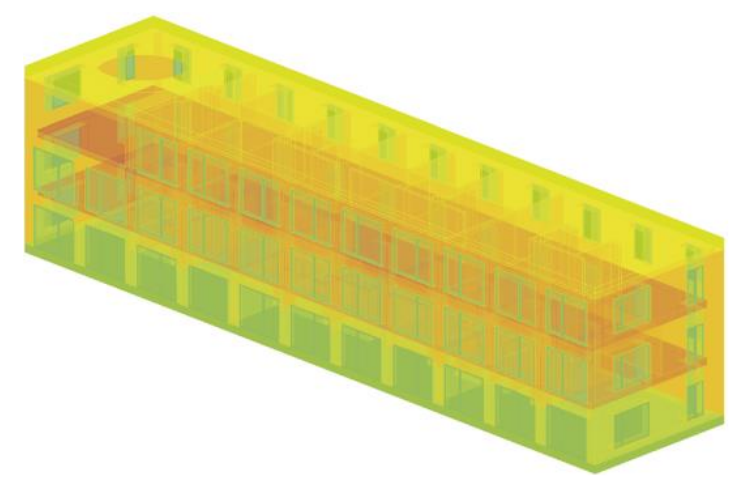

Figure 7. Mapping the results onto the 3D model to show improvement potential [27].

In the future, we will also link Bombyx to other tools for performance assessment, such as daylight analysis or structural analysis. The modular and quick calculation approach are ideal for employing optimizers, for example genetic algorithms. Furthermore, the parametric approach allows for employing machine-learning algorithms. A starting point could be to train these algorithms with saved data from student exercises to predict optimal materials and components for the geometry in either design or optimization stage. This step would significantly increase the quality and speed of the design, but would still need human verification.

\section{Acknowledgements and remarks}

We would like to thank the Innovedum fund of ETH Zürich for supporting for this project. We encourage every interested researcher, student and practitioner to collaborate on this open-source project.

\section{References}

[1] UNEP SBCI, "Building Design and Construction : Forging Resource Efficiency and Sustainable Development," 2012.

[2] A. Passer, H. Kreiner, and P. Maydl, "Assessment of the environmental performance of buildings: A critical evaluation of the influence of technical building equipment on residential buildings," Int. J. Life Cycle Assess., vol. 17, no. 9, pp. 1116-1130, May 2012.

[3] H. König and M. L. De Cristofaro, "Benchmarks for life cycle costs and life cycle assessment of residential buildings," Build. Res. Inf., vol. 40, no. 5, pp. 558-580, 2012.

[4] B. Wittstock, S. Albrecht, C. Makishi Colodel, J. P. Lindner, G. Hauser, and K. Sedlbauer, "Gebäude aus Lebenszyklusperspektive - Ökobilanzen im Bauwesen," Bauphysik, vol. 31, 2009.

[5] B. C. Paulson Jr., "Designing to Reduce Construction Costs," J. Constr. Div., vol. 102, no. 4, pp. 587-592, 1976.

[6] M. Hegger, M. Fuchs, T. Stark, and M. Zeumer, Energie Atlas: Nachhaltige Architektur. Birkhäuser, 2007. 
[7] U. Bogenstätter, "Prediction and optimization of life-cycle costs in early design," Build. Res. Inf., vol. 28, no. 5/6, pp. 376-386, 2000.

[8] D. Davis, "Modelled on Software Engineering: Flexible Parametric Models in the Practice of Architecture," RMIT University, 2013.

[9] B. Lawson, Design in Mind. Butterworth Architecture, 1994.

[10] A. Hollberg, "A parametric method for building design optimization based on Life Cycle Assessment," Bauhaus University Weimar, 2016.

[11] C. Cavalliere, G. Habert, G. R. Dell'Osso, and A. Hollberg, "Continuous BIM-based assessment of embodied environmental impacts throughout the design process," J. Clean. Prod., vol. 211, pp. 941-952, Feb. 2019.

[12] M. Thumfart, “Tortuga," 2016. [Online]. Available: https://www.food4rhino.com/app/tortugalca-grasshopper.

[13] CAALA GmbH, "Computer-Aided Architectural Life cycle Assessment (CAALA)," 2018. [Online]. Available: www.caala.de. [Accessed: 02-Feb-2019].

[14] SIA, "Tool SIA 2040 Effizienzpfad Energie," 2017. [Online]. Available: https://www.energytools.ch/index.php/de/downloads/tools/download/2-tools/66-tool-sia-2040d. [Accessed: 03-Mar-2019].

[15] A. Hollberg and J. Ruth, "LCA in architectural design — a parametric approach," Int. J. Life Cycle Assess., vol. 21, no. 7, pp. 943-960, Jul. 2016.

[16] A. Hollberg, Parametric Life Cycle Assessment - Introducing a time-efficient method for environmental building design optimization. Bauhaus-Universitätsverlag, 2016.

[17] EN 15978, "Sustainability of construction works - Assessment of environmental performance of buildings - Calculation method," 2011.

[18] KBOB, "Ökobilanzdaten im Baubereich 2009/1:2016," 2016.

[19] SIA, "SIA 2032 Graue Energie von Gebäuden," no. 2010. Schweizerischer Ingenieur- und Architektenverein, Zürich, 2010.

[20] SIA, SIA 380 - Grundlagen für energetische Berechnungen von Gebäuden. 2015.

[21] UVEK and BAFU, "Die Methode der Umweltbelastungspunkte," 2008.

[22] R. Frischknecht and S. Büsser Knöpfel, "Ökofaktoren Schweiz 2013 gemäss der Methode der ökologischen Knappheit - Methodische Grundlagen und Anwendung auf die Schweiz,” 2013.

[23] IPCC, "IPCC Fourth Assessment Report: Climate Change 2007," 2007.

[24] E. Meex, A. Hollberg, E. Knapen, L. Hildebrand, and G. Verbeeck, "Requirements for applying LCA-based environmental impact assessment tools in the early stages of building design," Build. Environ., vol. 133, 2018.

[25] A. Hollberg, G. Habert, P. Schwan, and L. Hildebrand, "Potential and limitations of environmental design with LCA tools," Creat. GAME - Theory Pract. Spat. Plan., vol. 5, pp. 34-455, 2017.

[26] B. Kiss and Z. Szalay, "A Visual Method for Detailed Analysis of Building Life Cycle Assessment," in enviBuild - Buildings and Environment - From Research to Application, 2017.

[27] M. Röck, A. Hollberg, G. Habert, and A. Passer, "LCA and BIM: Visualization of environmental potentials in building construction at early design stages," Build. Environ., May 2018.

[28] A. Hollberg, T. Lützkendorf, and G. Habert, "Top-down or bottom-up? - How environmental benchmarks can support the design process," Build. Environ., vol. 153, pp. 148-157, Apr. 2019. 